\title{
Public evaluation of electricity technologies and future low-carbon portfolios in Germany and the USA
}

\author{
Dirk Scheer $^{1^{*}}$, Wilfried Konrad ${ }^{2}$ and Oliver Scheel ${ }^{1}$
}

\begin{abstract}
Background: This paper aims to create insights into people's technology preferences in striving to achieve a low-carbon electricity generation system. The investigation seeks to analyze informed rather than mere opinion-based public preferences towards electricity technologies and portfolios against the background of climate mitigation options. In order to compare Germany with its strong renewable energy focus with a more fossil fuel- and nuclear-oriented country, the study presented replicates a research carried out in the USA in order to deliver data enabling such comparison. A special focus is on assessing attitudes and opinions towards carbon capture and storage as a low-carbon technology option.

Methods: A mixed-method focus group approach has been elaborated and applied for 15 focus groups including a total of 130 participants nationwide. The approach first starts off with a traditional focus group design, i.e., discussion rounds with 8 to 10 participants led by a facilitator in order to collect qualitative data. This traditional focus group approach is extended by a quantitative survey design where participants had to fill out several closed-question questionnaires before and during the discussion rounds.

Results: Main quantitative results presented in this article consist of an electricity technology ranking and an electricity portfolio ranking. The results show considerable differences between US and German participants. While nuclear energy and the carbon capture and storage technology option are high ranking in the USA, German participants clearly favor renewable energies.

Conclusions: The comparison made clear that the stated preferences show a country bias, revealing a unique profile of technology and portfolio preferences in the USA and Germany. The policies that lie ahead of society need to find approval by stakeholders and the public at large, and therefore need to integrate acceptance profiles into communication and information activities.
\end{abstract}

Keywords: Public preferences, Informed decision, Technology acceptance, Electricity technologies and portfolios

\section{Background}

The research presented within this paper investigates public preferences of electricity-generating technologies and future electricity portfolios among German citizens. It replicates a study carried out in Pennsylvania in the USA [1] in order to deliver comparable results between the US and the German case study. The methodological reason for relying on a comparative approach instead of

\footnotetext{
* Correspondence: dirk.scheer@sowi.uni-stuttgart.de

${ }^{1}$ Stuttgart Research Center for Interdisciplinary Risk and Innovation Studies (ZIRIUS), Stuttgart University, Seidenstraße 36, Stuttgart 70174, Germany Full list of author information is available at the end of the article
}

carrying out a single case study lies in the opportunity to scrutinize the influence of country differences on preference profiles. In this respect, the USA seems to be a highly suitable reference area as it offers the possibility to compare a country relying on renewable energies with a region mainly focusing on fossil fuels and nuclear energy. Though the research design had to be adapted to country specifics in Germany to some extent, comparability with the US results was still achieved. The intercountry comparison allows us to look deeper into both the suitability of the methodology used and the variance and level of technology preferences differing by countries. 
The country comparison reveals similarities and differences in preference distribution among respondents. As a considerable legitimacy resource, preferences impact and shape current and future energy policies. Thus, decisions about the future energy supply are not just about selecting the one and only best power plant option. Rather, the task is to create a balanced combination of various plant types which meet the complex interrelated requirements of technical feasibility, economic and environmental soundness, and social acceptability.

The transformation of the energy sector is currently on a wide range of policy agendas in both developing and less developed countries. A major stimulus for energy transformation efforts is due to the problem of global warming and climate change. $\mathrm{CO}_{2}$ emissions from energy industries in the European Union, for instance, account for around $40 \%$ of total emissions with the lion's share stemming from public electricity and heat production [2]. Since fossil fuel-based electricity production forms the backbone in many countries, a transformation towards a low-carbon energy portfolio is the key to reach the climate policy objective, reducing $\mathrm{CO}_{2}$ emissions by $80 \%$ to $95 \%$ in 2050 compared to 1990 [3]. Thus, nothing less than a revolution in energy systems is required, replacing high-carbon electricity-generating technologies with low-carbon ones.

Germany when announcing the Energiewende (or energy turnaround) after the events in Fukushima has committed itself to the most ambitious challenge in turning the energy sector away from fossil fuel and nuclear energy. That is why we have chosen to contrast Germany against the USA: The German debate since is marked by several catchwords, making great demands for the transformation process. In a nutshell, the transformation shall be climate- and environment-friendly, secure energy supplies, guarantee planning reliability and competitiveness for companies, leave energy prices at a level affordable for everyone, and last but not the least, meet public acceptance.

Public acceptance has been recognized as a crucial factor for transforming the energy system $[4,5]$. Social acceptance in the field of energy has been conceptualized on three dimensions [4]. The first dimension covers social-political acceptance at the broadest level where both policies and technologies can be subject to societal acceptance. Second, community acceptance refers to siting decisions and local to regional risk-benefit trade-offs. Third, market acceptance refers to the diffusion processes of new electricity technologies under market conditions. Most acceptance studies on energy technologies refer to the first and second dimensions, identifying motives, preferences and goals making up acceptance [6-8].

A common feature in energy-related acceptance research is its single technology orientation. The large majority of acceptance research considers just one or at best - a few similar technologies (e.g., a set of renewable technologies) but does not take the whole range of relevant power technologies into account. Several studies examined the public perception and acceptance of nuclear energy $[9,10]$, the capture and storage (CCS) technology ${ }^{\mathrm{a}}$ [11-13], wind energy [6,14] and photovoltaics (PV) [15] or a set of renewable energies [16,17]. Acceptance research for fossil fuels such as coal or natural gas plants, however, is rare. Results from perception research and large national samples indicate, in general, high support for renewable energy technologies and an overall reluctance for nuclear energy and concerns on the CCS technology. Looking at Germany, for instance, various large surveys unanimously show high levels of societal support for renewables [18-20].

In-depth studies on one or a few similar electricitygenerating technologies hide the impact of alternatives and 'competing' technology evaluation on acceptance judgments. A crucial feature of acceptance is to choose between different options and corresponding balancing of reasons and preferences. Acceptance as an active/passive and voluntary act is a decision based on value judgments. A decision requires options to choose from. This understanding of acceptance draws on insights gained from risk perception research [21,22]. In the field of energy, a large variety of electricity-generating technologies are at hand each with its unique profile of implications, consequences, and challenges. Risk perception and technology acceptance research taught us the relevance of a great variety of qualitative acceptance factors influencing laypeople's judgments on technologies [23-25]. Among others, voluntariness, controllability, well-balanced distribution of risk and benefits, and trust are relevant factors influencing acceptance. Expressed preferences by citizens reflect considerations of pros and cons for several technologies and sum up for acceptance or rejection. Thus, to better simulate real-world public evaluation processes, it is in our view necessary to let participants do a multi-technology assessment where one technology option can only be evaluated compared to similar alternatives. We therefore have chosen 12 electricity-generating technologies and 7 low-carbon electricity portfolios that could be realistically relevant in Germany over the next 25 years.

Taking a set of relevant technologies as object of investigation raises the question on the participants' level of knowledge. Knowledge is an essential category to make an objective assessment [26,27]. Literature shows that the level of knowledge on electricity technologies is at best modest with people having a low level of information and knowledge about new energy technologies and who are unable to discriminately rank them $[8,28]$. A striking example is the carbon capture and storage 
technology where people have, on average, a low level of knowledge [29-33]. As a result, people tend to have 'pseudo-opinions' or non-attitudes with a low level of stability over time. Expressed preferences based on pseudo-opinions are of low value. Social scientists therefore often provide beforehand information to people on the object of investigation. As a consequence, informed preferences seem more stable and enduring [34-36]. Since the array of energy technologies is complex and the future energy mix will be a highly integrated system, we elicited informed preferences within this study, providing well-balanced information before measuring preferences.

\section{Methods}

\section{The mixed-method focus group approach}

The approach for conducting empirical research in this study had to fulfill two requirements. First, the methodology used had to be in line with the US reference study [1] in order to deliver comparative results between the US and the German case study. Hence, participants were informed before group discussion with a well-balanced information material on electricity technology and future portfolio options. The authors elaborated the information package material. Before handing it out to participants, the information package was evaluated positively in a blind peer review process. Preferences, attitudes, and evaluations were elicited only after participants have read the material; thus, informed public preferences were collected. Preferences are understood as an evaluative judgment leading to a decision to favor or non-favor an object. Moreover, participants had to choose and evaluate within the whole range of technologies and future energy mixes without being able to focus on just one technology option. Thus, the participants' evaluative judgment as a stated preference was imbedded in a realistic showcase environment where trade-offs and complexities between technological alternatives play a role. Second, to analyze preferences, attitudes, and their underlying reasoning patterns, a mixed quantitative and qualitative approach was used. On one hand, this allowed measuring quantitatively preferences and the impact of variables, while on the other hand, this delivered inductive categories disclosing reasoning patterns.

To meet these requirements a mixed-method or hybrid focus group approach has been elaborated [37]. The approach first starts off with a traditional focus group design [38-40], i.e., discussion rounds with 8 to 10 participants led by a facilitator in order to collect data as of 'words spoken by participants' [41]. The focus groups were fully tape-recorded and transformed in verbatim transcription. This traditional focus group approach has been extended by a quantitative survey design where participants had to fill out several closed-question questionnaires before and during the discussion round. Several survey sheets covered topics such as technology and portfolio mix ranking, comprehensions and impact of information material on preferences, attitudes on climate change and carbon capture and storage, 'not in my backyard' (NIMBY) survey, and socio-demographics. Table 1 summarizes core elements of the mixed-method design focus group approach.

To illustrate the mixed-method design in practice, participants were required to fill in ranking sheets and document the ranking of electricity technologies and portfolios. Participants were presented with an introduction to climate change policy goals of the German government with the following work task:

Please envision the German government needs your advice and is asking for your opinion how the electric power supply should be in the year 2035. For the time being many power plants are at the end of its life-span and need to be replaced by others. So the question is: which power plant technologies should in your opinion replace the old ones? It is your task to rank the following electricity generating technologies from best to worst as you think it is desirable.

Table 1 Two pillars of mixed-method design focus groups

\begin{tabular}{|c|c|c|}
\hline & Homework & Group discussion \\
\hline \multirow{2}{*}{$\begin{array}{l}\text { Information for } \\
\text { participants }\end{array}$} & Information package: & Information package: \\
\hline & $\begin{array}{l}\text { ca. } 30 \text { pages with information on } 12 \text { electricity technologies } \\
\text { and both a technology cost comparison and pollution } \\
\text { comparison sheet }\end{array}$ & $\begin{array}{l}\text { ca. } 7 \text { pages with information on } 7 \text { electricity portfolios and both a } \\
\text { portfolio cost comparison and pollution comparison sheet }\end{array}$ \\
\hline \multirow{4}{*}{$\begin{array}{l}\text { Method of data } \\
\text { collection }\end{array}$} & Quantitative surveys: & Quantitative surveys: \\
\hline & $\begin{array}{l}\text { Total of } 24 \text { closed questions with surveys on ranking } \\
\text { technologies, attitude on climate change, NIMBY, } \\
\text { comprehension and impact of information on } \\
\text { preferences }\end{array}$ & $\begin{array}{l}\text { Total of } 14 \text { closed questions with surveys on ranking technologies } \\
\text { and portfolios, comprehension and impact of information on } \\
\text { preferences, carbon capture and storage }\end{array}$ \\
\hline & Qualitative: & Qualitative: \\
\hline & None & Tape recording and verbatim transcription of group discussions \\
\hline $\begin{array}{l}\text { Requirements for } \\
\text { participants }\end{array}$ & Reading of information package and filling out of surveys & $\begin{array}{l}\text { Explanation of preferences and attitudes towards technologies } \\
\text { and portfolios, and filling out of surveys }\end{array}$ \\
\hline
\end{tabular}


In order to observe group interaction and impacts on individual opinions, the ranking exercise was carried out individually and collectively during different points of time, that is, an individual ranking at the beginning, a collective ranking where all participants had to agree on one ranking representing the preferences of the whole group in the middle of the discussion, and a final individual ranking at the end of the focus group. Besides this survey-based exercise, participants were also requested to give reasons for the ranking position and explain their preferences and attitudes for the one or other technology and portfolio. As a result, quantitative and qualitative data have been collected combining number-based ranking results with reasoning and evaluation patterns. Analyses of quantitative data have been done with SPSS software using descriptive statistics.

\section{Materials}

Electricity technologies and portfolios took center stage in the research both as core elements of the information material and the evaluation exercise. Technologies and portfolios had to fulfill three requirements. First, chosen technologies shall be technical feasible from today's perspective within the next 25 years, or to be more precise in the year 2035. Second, the selection shall be in principle comparable to the US reference study, and third, notwithstanding requesting international comparability, it should take country specifics of the German electricity and energy landscape into account.

We have chosen the following 12 electricity technologies judged to be relevant in 2035 (compared to 10 in the US study):

- Four coal-based technologies, i.e., one so-called traditional coal plant (pulverized coal, PC) and one so-called modern coal plant (integrated gasification combined-cycle coal, IGCC), each with and without CCS;

- Natural gas combined cycle;

- Nuclear power plants (second generation, i.e., we did not consider building of new nuclear power plants in Germany);

- Five renewable energy sources such as wind onshore, wind offshore, photovoltaics, solar thermal energy (DESERTEC ${ }^{\mathrm{b}}$ ), and biomass; since the US study focuses on Pennsylvania, wind offshore and DESERTEC do not belong to the technologies chosen to be ranked;

- Energy efficiency.

In our view, this selection guarantees comparability with the US study and is based on energy market and technology features in Germany. We did not consider both hydro power since current capacity is already set to the maximum and geothermal power which foremost relates to heat energy production. Energy efficiency has been added to be in line with the US study.

The information package handed out to participants before the group discussion contained several elements. Each electricity-generating technology has been described on a technology sheet summarizing its functioning and current relevance (e.g., share at the energy mix 2010 and cross-electrical output) and main environmental and economic impacts (e.g., emissions, water and resource consumption, construction and electricity costs), and synthesizing the main advantages and disadvantages. Moreover, the information package entailed supplementary technology sheets covering explanations on the electric grid and the carbon capture and storage technology. In addition, pollution and cost comparison sheets estimating future environmental and economic impacts were given to participants. Percentage-based comparisons illustrated differences between technologies in, for instance, $\mathrm{CO}_{2}$, nitrogen oxides, sulfur dioxides, and mercury. Cost comparisons were based on monthly best estimate cost for a four-person household including error bars for representing uncertainty. Table 2 illustrates the ranking exercise for electricity technologies used in homework and discussion rounds.

Seven electricity portfolios have been elaborated to be in line with the US reference study. Comparability of portfolios is given due to its similar $\mathrm{CO}_{2}$ reduction corresponding to the German government's climate change policy objectives which foresee to reduce $80 \%$ of $\mathrm{CO}_{2}$ emissions in 2050 compared to 1990. All seven portfolios reduce $\mathrm{CO}_{2}$ emissions by ca. $60 \%$ in 2035 compared to 1990. Elaboration of the portfolios focused on three principles: corresponding to climate protection strategies

Table 2 Example of quantitative survey sheet (evaluation of electricity technologies)

\begin{tabular}{l}
\hline Electricity technology \\
\hline Energy efficiency \\
\hline Traditional coal power plant \\
\hline Traditional coal power plant with CCS \\
\hline Modern coal power plant \\
\hline Modern coal power plant with CCS \\
\hline Modern natural gas plant \\
\hline Nuclear power plant \\
\hline Wind power - onshore \\
\hline Wind power - offshore \\
\hline Photovoltaics \\
\hline Solar thermal power plant \\
\hline Biomass
\end{tabular}

Please fill in your power plant ranking in the table below. Consider that ' 1 ' is the best and ' 12 ' is the worst ranking position. Write down your ranking in the empty slots in the right column. Please be aware to use each number (1 to 12) only one time. Source: own depiction. 
in the power sector, reflecting the state of the art in literature, and being clearly identifiable by participants.

Carbon-low energy portfolios can be clustered around their primary energy source emphasis. One might distinguish a fossil fuel-based, nuclear-based, and renewable-based carbon-low portfolio strategy. First, a fossil fuel-based strategy lays emphasis on traditional and modern coal and natural gas power plants combined with carbon capture and storage technologies. In this strategy, $\mathrm{CO}_{2}$ reduction is mainly achieved through CCS though nuclear and renewable energies may supplement the portfolio. This strategy applies to countries which currently heavily rely on coal and gas power plants such as the USA, Germany, India, or China.

Second, a nuclear strategy achieves climate reduction goals with $\mathrm{CO}_{2}$ emission-free nuclear power plants. The current electricity portfolio of France is an example of a nuclear low-carbon strategy. The renaissance of nuclear power in the last decades is foremost based on its carbon low potential. However, public opposition in several countries limits construction of new nuclear power plants. Therefore, other low-carbon technologies such as coal with CCS or renewable energies may contribute to this portfolio.

Third, a renewable energy strategy focuses on considerable shares of renewable energy in the electricity portfolio to reach a long-term goal of $100 \%$. In the bridging period where renewable storage plants are still lacking, there is a need for backup by other power plants. When renewable energies are backed by CCS, nuclear energy can be neglected; when backed by nuclear energy, CCS plays only a minor role. Taking these strategies as an ideal type-based starting point, we elaborated the following seven portfolios for the German context, taking energy scenario results from literature into account [42-44] (see Table 3).

\section{Participants}

In total, 15 mixed-method designed focus groups including 130 participants have been carried out nationwide. As a distinctive feature, we have chosen focus group locations according to an urban vs. rural, east vs. west, and CCS-affected vs. non-affected dimension. Discussion rounds were held, for instance, in Cologne and Stuttgart (city, west, non-CCS-affected), Rielingshausen (rural, west, non-CCS-affected), Neutrebbin (east, CCS-affected), and Berlin (city, east). CCS-affected relates to regions where $\mathrm{CO}_{2}$ storage was planned. In Germany, in the Land of Brandenburg around Neutrebbin and Beeskow, the energy supplier Vattenfall planned a CCS storage demonstration project. However, the project has been canceled in the meantime due to severe local opposition and a lack of a regulatory CCS framework.

Besides siting differentiations, we did not apply other parameters for recruiting participants. Thus, we announced planned focus groups within chosen locations via, for instance, email databases, notifications in town halls, and community organizations and recruited participants in order of response. We financially compensated participants with 85 Euro per person since homework and group discussion altogether on average lasted around $5 \mathrm{~h}$. Among the 130 participants, $41.5 \%$ were female and $54.8 \%$ were male, while $3.8 \%$ did not indicate the gender. Participants were on average 41.3 years old (standard

Table 3 Composition of low-carbon electricity generation portfolios

\begin{tabular}{|c|c|c|c|c|c|c|c|}
\hline & \multicolumn{2}{|c|}{ Fossil strategy } & \multicolumn{2}{|c|}{ Nuclear strategy } & \multicolumn{3}{|c|}{ Renewable strategy } \\
\hline & $\begin{array}{l}\text { Fossil classical } \\
\text { and CCS (\%) }\end{array}$ & $\begin{array}{l}\text { Fossil modern } \\
\text { and CCS (\%) }\end{array}$ & $\begin{array}{l}\text { Nuclear and } \\
\text { CCS (\%) }\end{array}$ & $\begin{array}{l}\text { Nuclear no } \\
\text { CCS (\%) }\end{array}$ & $\begin{array}{l}\text { Renewable } \\
\text { CCS (\%) }\end{array}$ & $\begin{array}{l}\text { Renewable } \\
\text { no CCS (\%) }\end{array}$ & $\begin{array}{l}\text { Renewable } \\
\text { 'ambitious' (\%) }\end{array}$ \\
\hline Fossils total & 78 & 78 & 56 & 46 & 55 & 45 & 35 \\
\hline$P C$ & 8 & 18 & 25 & 10 & 20 & 12 & 25 \\
\hline PC with CCS & 40 & & & & & & \\
\hline IGCC & 15 & 5 & & 18 & 20 & 15 & \\
\hline IGCC with CCS & & 39 & 21 & & 8 & & \\
\hline Natural gas & 15 & 16 & 10 & 18 & 7 & 18 & 10 \\
\hline Nuclear total & & & 24 & 24 & & 10 & 5 \\
\hline Nuclear power plant & & & 24 & 24 & & 10 & 5 \\
\hline Renewable total & 22 & 22 & 20 & 30 & 45 & 45 & 60 \\
\hline Wind offshore & & & & & 16 & 7 & 15 \\
\hline Wind onshore & & & & & 8 & 8 & 10 \\
\hline Solar PV & & & & & 5 & 1 & 5 \\
\hline Solar thermal & & & & & & 22 & 15 \\
\hline Biomass & & & & & 16 & 7 & 15 \\
\hline
\end{tabular}


deviation (SD) 15.4); this is considerably younger compared to representative surveys of the ALLBUS ${ }^{\mathrm{C}}$ with an average age of 49.5 years old. Education level among participants was higher compared to the German average level with $46.3 \%$ having completed a university degree, $19.8 \%$ having graduated from high school, and only $4.1 \%$ having a certificate of secondary education. By comparison, the representative ALLBUS survey finds 13.5\% completing their studies, $24.3 \%$ finishing high school, and $35.7 \%$ disposing of a certificate of secondary education, while $37.1 \%$ did advanced technical college. Net household income on average was between 2,000 and 2,500 $€$ which is close to that reported by ALLBUS where net household income is identified as of $2,510 €$ per month.

\section{Results}

\section{Technology rankings}

Figure 1 shows the German quantitative ranking results (right column) of the 12 electricity-generating technologies before and after group discussion on a scale from 1 (best technology) to 12 (worst technology) compared to the results in the USA (left column) with the German results scaled down to the 10 -item US ranking scale.
Taking a closer look at the German ranking before discussion, it reveals a clear prioritization according to primary energy source. Energy efficiency - which is in a true sense no electricity-generating technology - is clearly ranked first place. All single renewable technologies follow with wind and solar thermal (as DESERTEC) being the best. Surprisingly, biomass lags behind the set of renewable ranking slightly better than natural gas power plants - the latter leading the set of fossil fuel power plants. Coal power plants follow in sequence of their scale of modernity and than their level of $\mathrm{CO}_{2}$ emission. A modern coal plant is favored against a traditional pulverized coal plant with CCS retrofit. Nuclear power plants share the last position with pulverized coal plants.

Ranking after discussion reveals some interesting results. First, stability of opinions is overall very strong. Post-discussion ranking just slightly differs compared to the pre-discussion ranking with only two ranking positions having changed: wind onshore ranks third displacing solar thermal on the fourth position, while nuclear and pulverized coal swap the last rank. Second, the group discussion accentuated the primary energy source prioritization pattern. The renewable energies

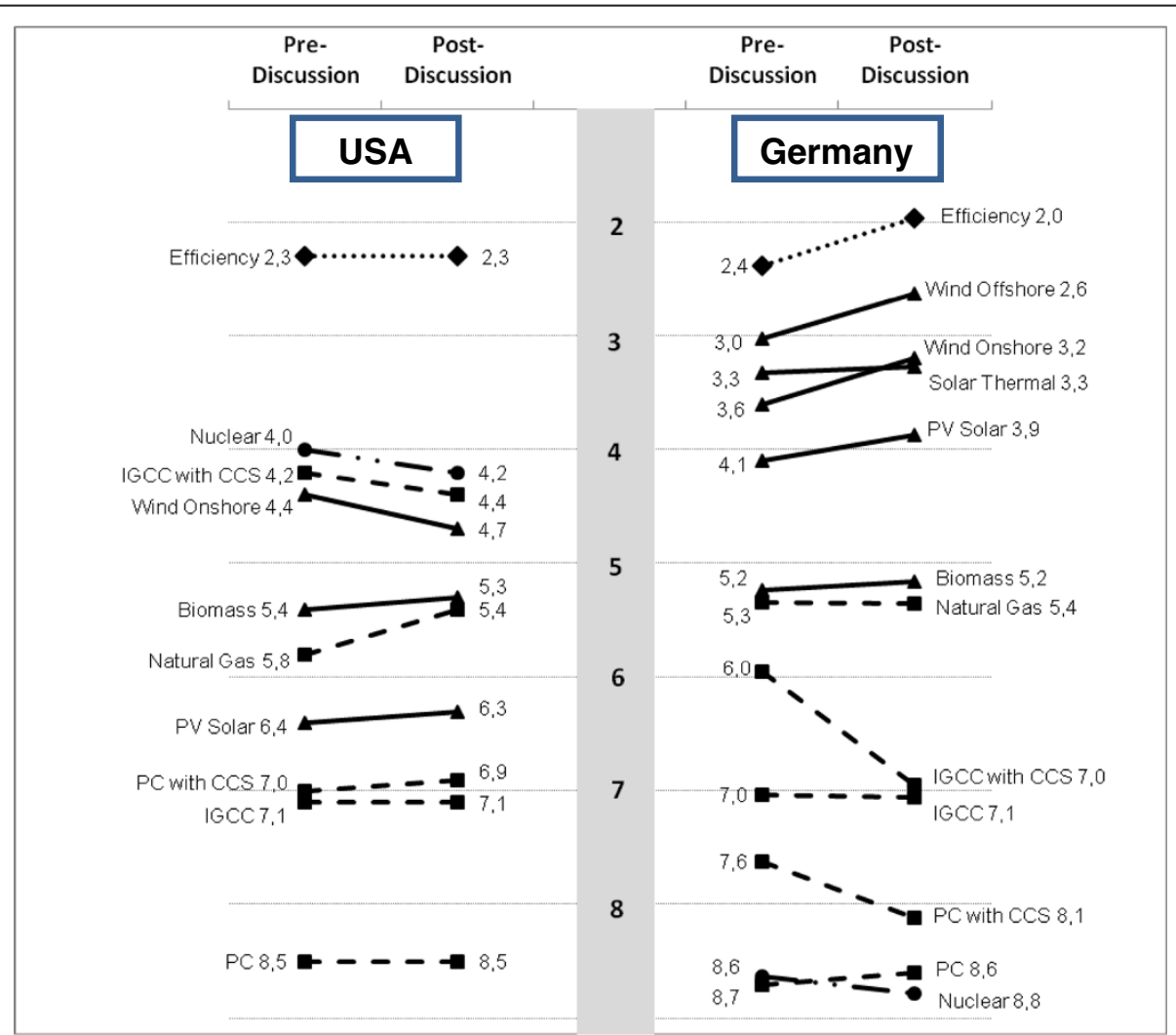

Figure 1 Participants' mean technology ranking before/after group discussion in the USA and Germany. Dotted lines refer to energy efficiency, two-dotted lines refer to nuclear energy, solid lines refer to renewable energies, and dashed lines refer to fossil energies. Source: left column [1]; right column own depiction. 
improved their leading position, while the fossil fuels at best stabilized at their former ranking position. Third, coal plants with CCS technologies considerably were losing preferences during the discussion. IGCC with CCS is ranked after discussion roughly on the same level as an IGCC plant without CCS, and even the pulverized coal plant with CCS ends up slightly better than its counterpart without CCS. Safety worries within the $\mathrm{CO}_{2}$ storage stage which is independent of the type of plant have been the primary argument for ranking deterioration during the discussion. Statistical analysis confirms the observations. Kendall's coefficient of concordance $(W)$ tested the consistency of participants' personal ranking over all technologies (0.63 at high significance $p=0.00$ ).

Socio-demographic variables having a possible impact on ranking decisions have been analyzed. Correlations of age and education with a high ranking position were tested for pre-discussion and post-discussion rankings with the Spearman coefficient. The results show in general little and weak correlation effects. Among the 12 types of electricity-generating technologies, only two significant correlations were found. First, the younger the participants, the more they tend to ban power plants with CCS on ranking positions 10 to 12 . Spearman $\rho$ identifies the correlation between age and the CCS ranking with 0.172 at a significance of $p=0.074$. This trend intensifies after discussion with even stronger effects (Spearman $\rho=0.193)$ and better significance rates $(p=0.045)$.
Second, participants with a lower level of education tend to place wind onshore and offshore on positions 10 to 12 . However, during the discussion, this effect weakens with lower rates of significance. The Spearman correlation between low education and wind energy drops from $\rho=0.218$ (at $p=0.028$ ) before the discussion down to $\rho=0.191$ at a significance of 0.058 afterwards. Besides, no further correlations between age and education, and ranking decisions were found.

\section{Portfolio rankings}

Main emphasis during group discussion has been on prioritization and ranking of the seven portfolios, each reducing $\mathrm{CO}_{2}$ emissions by ca. $60 \%$ in 2035 compared to 1990. Figure 2 shows the arithmetic mean of the individual rankings before and after group discussion for Germany (right column) and the USA (left column). The German data reveal first that there is no change of ranking positions before and after discussion. Exchange of arguments between and interaction among the participants did not yield fundamental re-evaluation of a single portfolio. Stability of opinion among participants is a consistent and remarkable feature throughout the deliberation. Second, again portfolio mixes rank according to their primary energy source-based climate strategy with renewable portfolios leading the ranking. Participants obviously clearly identified the underlying resource-based climate strategy foci and arranged the ranking alike. Renewable portfolios

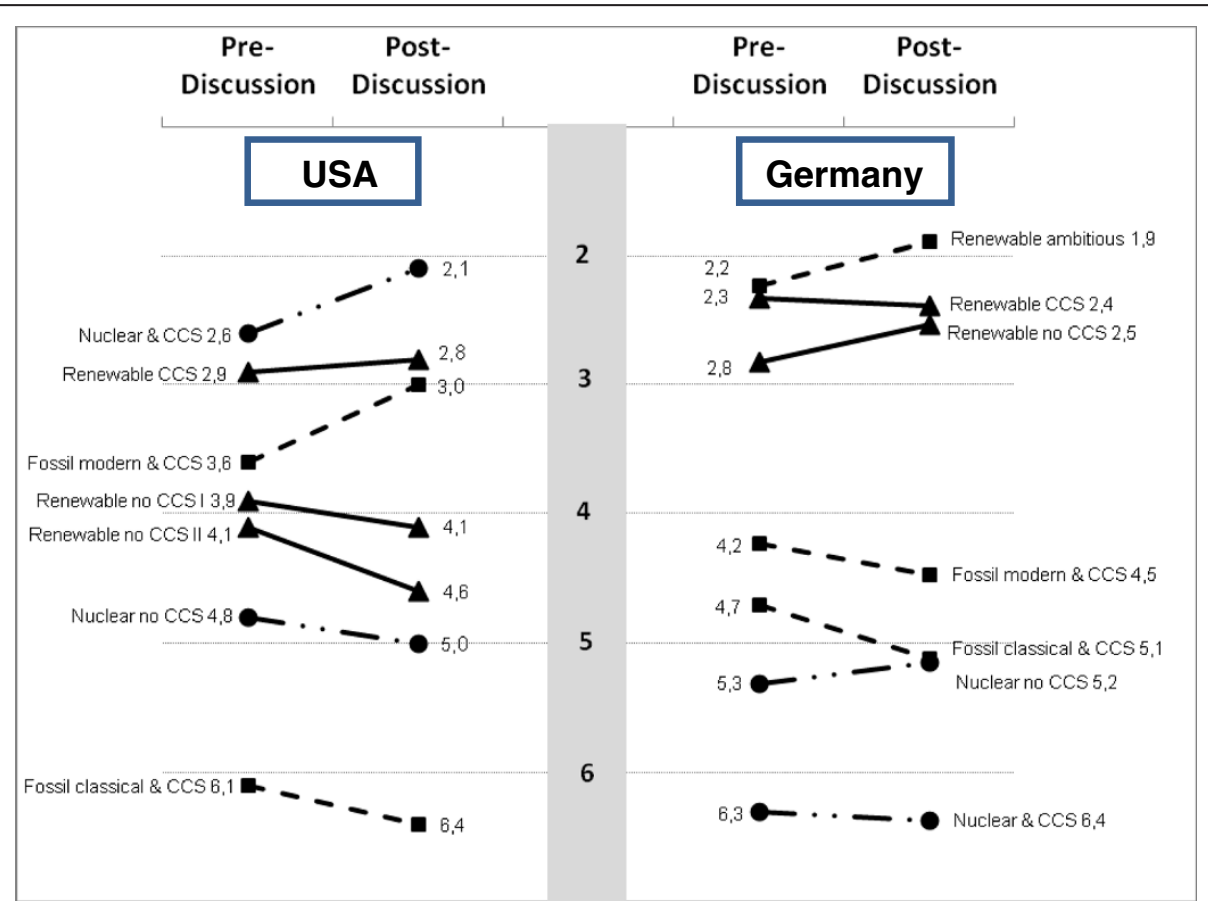

Figure 2 Participants' mean portfolio ranking before/after group discussion in the USA and Germany. Source: left column [1]; right column own depiction 
spearhead the ranking with the 'ambitious' portfolio consisting of $60 \%$ alternative energy composition on top. The bundle of fossil fuel-based strategies follows with clear distance, while nuclear portfolios rank last. Third, again group interaction reinforced the top leading position and cemented the structure with broadened distances between the preferred renewable portfolios and the disregarded bundles of fossil fuel and nuclear mixes.

Taking a closer look within the portfolio composition, it is striking that each energy mix with emphasis on carbon capture and storage technologies deteriorates after discussion. A coal-based strategy with retrofitting CCS loses most ground. On the contrary, combinations of renewable and nuclear energies all improve during the discussion. Apparently, established disliked technologies such as nuclear are favored against new-to-build disliked technologies such as CCS. The top-ranking 'ambitious' renewable portfolio with $60 \%$ share of alternative energies also encompasses $5 \%$ of nuclear and $25 \%$ of traditional pulverized coal plants. Nevertheless, the portfolio notably improved its position during the group discussion. One may conclude the following: with a clear and ambitious transformation of the German energy system towards a $100 \%$ renewable electricity system, participants are willing to accept for a bridging period disliked technologies such as nuclear.

Age as a socio-demographic variable had considerable impact on portfolio ranking. With high significance for both ex-ante and ex-post assessments, correlations show that the younger the participants, the more they tend to rank one of the renewable portfolios on top of the list. Spearman's $\rho$ indicates a correlation with $r_{1}=0.265$ before the discussion and $r_{2}=0.253$ afterwards (significance varies between $p_{1}=0.003$ and $p_{2}=0.007$ ), while Kendall's $\tau-B$ calculates a correlation with $r_{1}=0.204$ and $r_{2}=0.202$ (significance varies between $p_{1}=0.003$ and $p_{2}=0.006$ ). On the contrary, the older the participants, the more they were willing to rank fossil fuel-based portfolios on higher positions. This effect becomes even stronger during discussions as Spearman's $\rho$ increases from $r_{1}=$ 0.166 to $r_{2}=0.203$ and Kendall's $\tau-B$ from $r_{1}=0.126$ to $r_{2}=0.155$. However, the correlation is only significant $\left(p_{2}=0.03\right.$ both correlates) in the post-discussion ranking, while the pre-discussion is insignificant $\left(p_{1}=0.062\right)$. Concerning education, there is no significant correlation between education and portfolio ranking. A very cautious interpretation suggests a weak correlation with a tendency of higher educated participants ranking a renewable portfolio on top after discussion. The Spearman $\rho$ indicates a slight correlation with $r=0.161$, while the non-linear Kendall $\tau-B$ is calculated with $r=0.141$ - both with an error chance around $10.5 \%$.

\section{Information comprehension and group interaction}

The research objective aimed at eliciting informed preferences among participants being informed beforehand with an extensive and well-balanced material on electricitygenerating technologies. Several survey sheets identified objective and subjective participants' comprehension and information impact on ranking decisions.

Objective comprehension was based on a 14 trueand-false knowledge question survey. On average, 92.3\% ( $\mathrm{SD}=0.273$ ) of correct answers were given by the participants which indicates a high level of material comprehension among the participants. Most incorrect answers referred to the CCS and solar thermal technologies. Ca. $20 \%$ of participants negated the fact that $\mathrm{CO}_{2}$ storage takes place much deeper than drinking water aquifers. Around $17 \%$ of respondents did not believe that solar thermal power plants can be supplemented with energy storage plants in order to deliver electricity on demand day and night. Results hint to the need that when dealing with newly developed technologies, high level of information and communication efforts are necessary.

Subjective comprehension was examined via selfassessment before and after group discussion. On a scale from 1 (very difficult to understand) to 7 (very easy to understand), participants on average reached a high level of understanding with an arithmetic mean of 5.56. All different information materials reached equivalent high levels of understanding: CCS information sheet 5.55, grid and energy efficiency 5.78 , different types of power plants 5.6, pollution comparison 5.78, and cost comparison 5.56. One may conclude that in spite of the large quantity of material, the information content was well received. Group interaction obviously clarified some misunderstanding and comprehension deficits since the mean average of subjective comprehension after discussion increased slightly to 5.82 . Considerable increase took place for all but one material type (i.e., cost comparison).

We likewise analyzed the impact of the information package on technology ranking decisions by subjective self-assessment. Mean average for the entire material before discussion has been 5.32 on a scale from 1 (not important at all) to 7 (very important). Like subjective comprehension, the average rate is high and far beyond the scale midpoint of 3.5. In detail, all types of information sheets scored on a comparable high level except the cost comparison sheet which considerably lagged behind. To conclude, cost comparison information $(M=4.79$; $\mathrm{SD}=1.78$ ) had the lowest impact on ranking decision, while information on CCS $(M=5.68 ; \mathrm{SD}=5.61)$, types of power plants $(M=5.6$; $\mathrm{SD}=1.58)$, and pollution comparison $(M=$ 5.42; $\mathrm{SD}=1.54$ ) had the highest impact. Interestingly enough, information impact on preferences decreased after discussion at a level of 5.09. The relevance of written information obviously declined during the group 
interaction, while arguments and perspectives of other participants gained importance. Once again, information on cost comparison did lose considerable impact.

Interaction among participants is a core element in group discussion. While exchanging arguments and preferences, opinions and different views are put up for discussion and may impact on formation of opinions. Hence, a key question is on the significance and impact of group interaction on individuals and vice versa, respectively. A so-called satisfaction questionnaire elicited self-assessment of participants' own contribution to the group discussion and group ranking plus the influence of the group on one's own ranking exercise. We computed Pearson's correlation test with a weak but positive correlation of a participant impacting the group discussion $(r=0.212)$, and the group discussion influencing an individual. The correlation is highly significant with $p=0.021$. Thus, a mutual impact from the group to an individual and vice versa can be stated. In other words, the more actively an individual participates in the group interaction, the more information from the group $\mathrm{s} / \mathrm{he}$ receives. The reverse argument is valid, too: the less a participant engages in the discussion, the less is the impact of the group's opinions and arguments on one's own preferences.

\section{Discussion}

The analysis above revealed a clear distribution of energy generation preferences among the participants. Both with respect to power technologies and future electricity portfolios, the majority of participants voted for an energy supply based on renewables. Fossil fuel power plants and nuclear energy clearly rank on the lower end of the preference scale, indicating rejection rather than acceptance. Preferences obviously focus first on ranking according to the primary energy source (i.e., renewable, fossil, nuclear) and then consider singular technologies.

Another important finding relates to the fact that technology and portfolio evaluations remained considerably stable between pre- and post-discussion. Post-discussion results even strengthened the confrontation and deepened the gap between favored renewable and dismissed fossil and nuclear energies. However, there is one major exception to this general rule, that is, the high degree of preference instability in the case of carbon capture and storage technology. Largely driven by worries about $\mathrm{CO}_{2}$ leakages and other risks at storage sites, both the CCS power plant types and CCS energy portfolios faced a remarkable decline of support during the group deliberations. At the beginning of the discussions, the acceptance level of modern and traditional coal plants with CCS were distinctively higher compared to IGCC and PC without CCS. After discussions, however, coal plants with CCS ranked only slightly better than those without CCS. With respect to the ranking of the energy portfolios, a preference shift from CCS-focused portfolios to combinations of nuclear and renewable energies can be observed. All portfolios with considerable shares of the CCS technology lost approval, while all portfolios based on nuclear power and renewables increased their preferences. This remarkable and, during the group discussions, growing unease with the potential climate protection technology CCS led us to carry out a deeper analysis of CCS assessment.

\section{Technology in focus: the acceptance of carbon capture and storage}

A key feature has been the analysis of ranking decisions and participants' climate-conscious action and attitudes. First, we investigated relationships of climate-conscious action and ranking positions of high $\mathrm{CO}_{2}$-emitting power plants (i.e., coal and natural gas plants). The survey on climate change was based on a selection of questions from the Eurobarometer report on Europeans' attitudes towards climate change [45]. Among others, personal action taken to fight climate change was surveyed. A regression analysis has been computed based on the hypothesis whether participants acting climatefriendly place high $\mathrm{CO}_{2}$-emitting electricity-generating technologies such as coal power plants without CCS and natural gas plants on the last four ranking positions. The relationship was clearly approved with the standardized coefficient beta value of 0.306 and $R^{2}=9.5 \%$. Taking the small sample into account, the coefficient is surprisingly high. Further calculations computed the regression without considering natural gas plants since these were estimated by participants as relatively positive. As a result, the relationship even became more apparent. Now climateconscious action impacts ranking of coal plants on the last four ranking positions with $\beta=0.501\left(R^{2}=25.1 \%\right)$. The variance value of above $20 \%$ is deemed as a success [46].

Second, we analyzed attitudes towards climate change and their impact on CCS technology rankings. The test researched whether participants with a climate-conscious attitude favor CCS technologies, ranking them on top. Results show no relationship at all with $\beta=0.082$ and $R^{2}=0.7 \%$. This is not surprising with regard to the fact that CCS skepticism among participants was very widespread. The CCS survey indicates that participants overwhelmingly dismissed the CCS technology. On a scale from 1 (high level of rejection) to 7 (high level of endorsement), the arithmetic mean is 2.87 which is significantly below the midpoint or 3.5, while the median is still lower with 2.79. Overall, the CCS technology is rejected by the large majority of participants.

A third test then analyzed the impact on ranking positions of CCS advocates. CCS advocates have been identified favoring CCS over a nine-item index within the CCS survey. We computed the impact of a positive 
attitude towards CCS on technology ranking, i.e., whether CCS advocates ranked the technology on positions 1 to 4 . As a result, the relationship was clearly approved with $\beta=0.538$ and $R^{2}=29 \%$. Taking the small size of CCS advocates into account, we interpret the data as a strong relation.

Summarizing the above presented data, we conclude that distinct attitudes towards climate change do not yield a positive evaluation and high ranking of the CCS technologies. In contrast, only a positive attitude towards CCS technologies ensures a high ranking, and thus, CCS preferences are compared to alternative existing electricitygenerating options. Climate-conscious actions clearly place $\mathrm{CO}_{2}$-emitting power plants (coal and natural gas plants without CCS) at the lower end of the ranking list, reflecting a rejection of these technologies.

\section{International comparison: contrasting the German and US results}

Beyond the fact that energy efficiency in both surveys appears to be the preferred electricity generation technology, striking differences are obvious between informed preferences among participants in Pennsylvania, USA and in Germany. The 10 set technology ranking in the USA [1] puts nuclear energy and IGCC with CCS at second and third place. Next follows the set of renewable energy technologies (wind power, biomass, PV solar) with only natural gas plants ranking sixth place in between biomass and PV solar. Most dismissed are coal power plants, that is to say, participants support traditional coal with CCS more than IGCC and pulverized coal both without CCS. The ranking proved considerably stable throughout the group deliberations with just a few changes in participants' evaluations. Nuclear, modern coal with CCS and wind onshore obviously lose acceptance, while on the contrary, natural gas seems to be a more attractive option at the end of the discussions.

When comparing the US with the German technology ranking, we find four striking disparities outstanding. First, nuclear energy is the most preferred power technology in the USA, while in Germany, it is the less favored. Second, though not so obvious, IGCC with CCS seems closely tied to nuclear energy: US participants rank modern coal with CCS at third place and nuclear second; the German survey puts IGCC with CCS at the eighth place which indicates a strong rejection. This finding is supported by comparing the overall CCS favorability ratings. While the US participants were slightly favorable (mean $=4.75$; $\mathrm{SD}=1.62$ ), German participants opposed the CCS technology by the majority. Third, in the US study, renewable energies attract only modest acceptance, while in Germany, renewables are the only electricity-generating technologies clearly preferred by most participants. This also sheds light on the fact that, fourth, the German ranking is strictly ordered according to primary energy source, while the US ranking provides a cross-energy source ranking.

The electricity portfolio ranking in the USA reveals similarities with the corresponding technology ranking. The nuclear and IGCC with CCS portfolio ranks clearly best, reflecting preferences already found in the technology ranking. The second placed renewable energy mix is followed by a fossil fuel-based energy mix with integrated CCS. At the very end of the ranking, we see a fossil fuel-based strategy representing a mix of PC with and without CCS. Once again as with the technology ranking, there is no change of ranking positions before and after discussion.

Taking both country data into account, the most striking difference between the US and German ranking is the opposed top and worst positioning: the best ranked portfolio in the USA appears to be the less preferred energy mix in Germany. This striking difference relates to the sharp preference assessments of both nuclear and CCS in these two countries. Another crucial distinction relates to the changes of mean rankings during the deliberations. While the US survey is characterized by both a growing acceptance for nuclear and fossil fuel-based portfolios and decreasing preference levels of renewable ones, the German post-discussion mean ratings partly changed the other way round.

The shared characteristics of the US and German data almost vanish behind these differences in both technology and portfolio rankings. As already mentioned above, the most preferred technology in both samples is energy efficiency; thus, participants seem to be highly attracted by the idea that using energy economically is the best way to contribute to a low-carbon energy generation. Two other similarities between the USA and Germany are remarkable. First, participants assign biomass and natural gas almost on the same preference level. Second, it is apparent that participants of both surveys unanimously are convinced that traditional coal plant without CCS is a highly undesirable power technology.

To conclude, comparing the results from both the US and German research sheds some light on how assessments of electricity-generating options are influenced by country specifics. Providing participants with proper and understandable information about technical features, pollutants, or costs enables them to discuss and decide upon energy-related preferences and options on a factoriented basis rather than just relying on mere opinions. However, as shown in the US and German rankings, decisions about whether technologies and energy mixes will be accepted or not are embedded in the wider social and economic context. Thus, the US findings may reflect the key role of coal and nuclear energy for Pennsylvania's economic structure, while the growing popularity of renewable 
energies in Germany had some influence on participants' preference building.

\section{Conclusions}

The main findings of our research relate to several issues. First, we observe clear informed preferences on low-carbon electricity generation technologies and portfolios among the German sample. Both technology and portfolio rankings favor unequivocally renewable energies, while fossil fuels and nuclear energy meet less acceptance. Second, socio-demographic variables to some degree explain the spectrum of stated preferences. Age is a predictor with younger participants dismissing the CCS technology and preferring renewable portfolios, while older participants tend to favor fossil fuel portfolios. Low levels of education impacts a low ranking of wind energies. Third, throughout the focus group exercise, participants revealed a high degree of stability of opinions towards technologies and portfolios. Opinion stability manifests in a twofold way: shifting positions between pre- and post-discussion ranking is absolutely rare, and the topped-ranked technologies/portfolios in general improve their score, while the last-ranked technologies/portfolios impair their score. In other words, opinion stability sharpens the contrast between top and worst ranking. However, the case of CCS clearly shows unstable opinions since the CCS technology after the discussion loses considerable support. Fourth, striking differences between the US and German preferences are obvious. While the Pennsylvanian sample favors nuclear energy and CCS, the German sample accepts only renewable technologies and portfolios. The comparison made clear that stated preferences show a country bias, revealing a unique profile of technology and portfolio preferences in the USA and Germany.

The policies that lie ahead of society need to find approval by stakeholders and the public at large. This applies specifically for future energy policies since securing a safe energy supply is a key challenge in terms of economic well-being, social equity, sustainability, or climate protection. In seeking public acceptance for energy strategies and decisions, communication and information play an important role. From our research, at least two insights as to the requirements on communication and information activities may emerge. First, it is not sufficient to focus on a single electricity technology or energy source (e.g., renewables). Informed citizens are able to assess several technologies in relation to each other, acknowledging, thus, the multi-faceted nature of creating a real-world instead of an ideal energy future. Beyond relying on a distinct and credible target of the transformation process of the electricity system, outreach actions need to take into account the various comparative technology preferences affecting the overall acceptability of a strategic approach. The German focus groups, for instance, have created evidence that the acceptance of nuclear energy as bridging technology is higher than that of modern coal plants equipped with CCS. For the USA, it could be shown that while pondering the pros and cons of alternative options, participants expressed a preference for portfolios including CCS and nuclear power. Second, communication and information activities need to be aware that informed preferences may come along with a high degree of stability. Thus, whatever the objectives of such measures might be providing information, creating acceptance, or enabling dialogue - one key to success will be clearness about how highly developed people's knowledge in a given domain is. Investigating this before launching specific outreach activities would allow characterizing different strategies for approaching different target groups. While some, for instance, may need arguments maintaining and enhancing their existing knowledge base in order to gain public attention and understanding, others should be addressed by highlighting issues that may contribute to a change in preferences.

Communication and information activities, hence, are only one pillar when it comes to promote public support. In recent decades, demands and concepts of integrating citizens and stakeholders in political decision-making have gained high significance. Public participation aims at embedding values, knowledge, preferences, etc. of affected individuals or groups into policies as a means to increase transparency and legitimacy of governance processes. With a view of organizing public participation in the energy system's transformation, our research suggests seeking for engagement methods which are able to cope with the complexity of a multi-technology approach. A promising way could be using conceptual or numerical simulation models to enable stakeholders to participate in energy-related decisions. Such 'participatory modeling' has mainly emerged in the field of natural resource management (e.g., fisheries, water management) and opens up the process of modeling to people who not as the modelers themselves are equipped with training and experience in the analysis and formal representation of systems [47]. Deliberatively exploring causal relationships of system components and impacts of behavioral or strategic choices supports social learning and creates shared views of problem definitions and solution options [48]. Participatory modeling exercises of possible future energy systems may foster consensus building, in terms of agreement and dissent, by enabling mutual understanding of feasible technologies and portfolios, appropriate transformation speeds, or acceptable cost increases. Providing insights to the impacts of varying decisions, participatory modeling could also be a means to challenge stable opinions that, as our research has shown, prevent stakeholders from considering alternative options. 


\section{Endnotes}

${ }^{a}$ Carbon capture and storage (CCS) is a technology where carbon dioxide mainly from point sources is captured before emitting into the air. After transport to a storage site, $\mathrm{CO}_{2}$ is then deposited underground in adequate geological formations in order to not enter the atmosphere as a contribution to climate change mitigation.

${ }^{b}$ DESERTEC is an initiative established in 2009 to promote and implement all kinds of renewable in sun-rich deserts with a special focus on northern African territories. Concentrating solar-thermal power plants together with heat storage tanks play a key role in the concept due to its ability to supply electricity on demand.

${ }^{\mathrm{c}}$ ALLBUS (Allgemeine Bevölkerungsumfrage der Sozialwissenschaften) is the German General Social Survey carried out biennially since 1980 as a representative, cross-sectional study to collect data on attitudes, behavior, and social structure in Germany.

\section{Abbreviations}

CCS: carbon capture and storage; IGCC: integrated gasification combined-cycle; M: arithmetic mean; PC: pulverized coal; PV: photovoltaics; SD: standard deviation.

\section{Competing interests}

The authors declare that they have no competing interests.

\section{Authors' contributions}

DS designed the study, analyzed the technology ranking, and drafted the manuscript. WK participated in designing the study, carried out the analysis of the portfolio ranking, and co-drafted the manuscript. OS performed the statistical analysis and was responsible for running the focus groups. All authors read and approved the final manuscript.

\section{Acknowledgments}

This research was made possible through financial support from the Stiftung Mercator. We also wish to thank our colleagues Ortwin Renn, Andreas Hohlt, and Frank Ulmer for participating in designing the study and running the focus groups. Last but not the least, we thank all citizens for their contributions within the focus groups, and three anonymous reviewers for their helpful comments and suggestions.

\section{Author details \\ ${ }^{1}$ Stuttgart Research Center for Interdisciplinary Risk and Innovation Studies (ZIRIUS), Stuttgart University, Seidenstraße 36, Stuttgart 70174, Germany. ${ }^{2}$ DIALOGIK Non-Profit Institute for Communication and Cooperation Research, Lerchenstraße 22, Stuttgart 70176, Germany.}

Received: 13 April 2013 Accepted: 15 April 2013

Published: 26 April 2013

\section{References}

1. Fleishmann L, Bruin de Bruin W, Morgan G (2010) Informed public preferences for electricity portfolios with CCS and other low-carbon technologies. Risk Anal 30:1399-1410

2. EU [European Union] (2010) EU energy in figures 2010. $\mathrm{CO}_{2}$ emissions by sector. Brussels. http://ec.europa.eu/energy/publications/doc/statistics/ ext_co2_emissions_by_sector.pdf. Accessed 24 July 2012

3. European Commission (2011) A roadmap for moving to a competitive low carbon economy in 2050. SEC(2011)288 final, Brussels

4. Wüstenhagen R, Wolsink M, Bürer MJ (2007) Social acceptance of renewable energy innovation: an introduction to the concept. Energy Policy 35:2683-2691

5. Raven RPJM, Mourik RM, Feenstra CFJ, Heiskanen E (2009) Modulating societal acceptance in new energy projects: towards a toolkit methodology for project managers. Energy 34:564-574
6. Devine-Wright P (2005) Beyond NIMBYism: towards an integrated framework for understanding public perceptions of wind energy. Wind Energy 8:125-139

7. Huits NMA, Molin EJE, Steg L (2012) Psychological factors influencing sustainable energy technology acceptance: a review based comprehensive framework. Renew Sustain Energy Rev 16:525-531

8. Assefa G, Frostell B (2006) Social sustainability and social acceptance in technology assessment: a case study on energy technologies. Technol Soc 29:63-78

9. Grove-White R, Kearnes M, Macnaghten P, Wynne B (2006) Nuclear futures: assessing public attitudes to new nuclear power. Polit Quart 77:238-246

10. Corner A, Venables D, Spence A, Poortinga W, Demski C, Pidgeon N (2011) Nuclear power, climate change and energy security: exploring British public attitudes. Energy Policy 39:4823-4833

11. van Alphen K, van Voorst tot Voorst Q, Hekkert MP, Smits REHM (2007) Societal acceptance of carbon capture and storage technologies. Energy Policy 35:4368-4380

12. Tokushige K, Akimoto K, Tomoda T (2007) Public perceptions on the acceptance of geological storage of carbon dioxide and information influencing the acceptance. Int J Greenh Gas Con 1:101-112

13. Wallquist L, L'Orange Seigo S, Visschers VHM, Siegrist M (2011) Public acceptance of CCS system elements: a conjoint measurement. Int J Greenh Gas Con 6:77-83

14. Jobert A, Laborgne P, Mimler S (2007) Local acceptance of wind energy: factors of success identified in French and German case studies. Energy Policy 35:2751-2760

15. Zhai P, Williams ED (2012) Analyzing consumer acceptance of photovoltaics (PV) using fuzzy logic model. Renew Energy 41:350-357

16. Zoellner J, Schweizer-Ries P, Wemheuer C (2008) Public acceptance of renewable energies: results from case studies in Germany. Energy Policy 36:4136-4141

17. Musall FD, Kuik O (2012) Local acceptance of renewable energy - a case study from southeast Germany. Energy Policy 39:3252-3260

18. European Commission (2006) Energy technologies: knowledge, perception, measures. Brussels. ftp://ftp.cordis.europa.eu/pub/fp7/energy/docs/ energy_tech_eurobarometer_en.pdf. Accessed 13 July 2012

19. TNS/Agentur für Erneuerbare Energien (2011) Hintergrundpapier Umfrage von TNS Infratest zeigt: Hohe Akzeptanz gegenüber Erneuerbaren Energien in Deutschland. http://www.unendlich-viel-energie.de/fileadmin/content/ Panorama/Akzeptanz/Factsheet_Umfrage_TNS_2011.pdf. Accessed 13 July 2012

20. Emnid/N24 (2011) Verbraucher: Verbraucher sind für Energiewende zu Opfern bereit. http://www.n-tv.de/ticker/Geld/Nerbraucher-sind-fuerEnergiewende-zu-Opfern-bereit-article3113166.html. Accessed 13 July 2012

21. Renn O, Zwick MM (1997) Risiko- und Technikakzeptanz. Springer, Berlin

22. Sjöberg $L$ (2002) Attitudes toward technology and risk: going beyond what is immediately given. Policy Sci 35:379-400

23. Covello VT (1983) The perception of technological risks: a literature review. Technol Forecast Soc 23:285-297

24. Slovic P (1987) Perception of risk. Science 236:280-285

25. Rohrmann B, Renn O (2000) Risk perception research - an introduction. In: Renn O, Rohrmann B (ed) Cross-cultural risk perception: a survey of empirical studies. Kluwer Academic Publishers, Dordrecht, pp 11-54

26. Siegrist M, Cvetkovich GT (2000) Perception of hazards: the role of social trust and knowledge. Risk Anal 20:713-719

27. Sjöberg $L$ (2001) Limits of knowledge and the limited importance of trust. Risk Anal 21:189-198

28. Reiner D, Curry T, Figueiredo M, Herzog H, Ansolabehere S, Itaoka K, Johnsson F, Odenbergeret M (2006) American exceptionalism? Similarities and differences in national attitudes toward energy policy and global warming. Environ Sci Technol 40:2093-2098

29. Curry TE, Ansolabehere S, Herzog H (2007) A survey of public attitudes towards climate change and climate change mitigation technologies in the United States: analyses of 2006 results. In: Publication No. LFEE 2007-01 WP. Massachusetts Institute of Technology, Laboratory for Energy and the Environment, Cambridge

30. Miller $E$, Bell $L$, Buys $L$ (2007) Public understanding of carbon sequestration in Australia: socio-demographic predictors of knowledge, engagement and trust. Aus J Emerg Tech Soc 5:15-33

31. Malone EL, Dooley JJ, Bradbury J (2010) Moving from misinformation derived from public attitude surveys on carbon dioxide capture and storage towards realistic stakeholder involvement. Int J Greenh Gas Con 4:419-425 
32. Pietzner K, Schumann D (ed) (2012) Akzeptanzforschung zu CCS in Deutschland: Aktuelle Ergebnisse, Praxisrelevanz, Perspektiven. Oekom Verlag, München

33. Ashworth P, Jeanneret T, Stenner K, Hobman EV (2012) International comparison of the large group process. Results from Canada, Netherlands, Scotland and Australia. CSIRO, Pullenvale

34. Cremer C, Esken A, Fischedick M, Gruber E, Idrissova F, Kuckshinrichs W, Linßen J, Pietzner K, Radgen P, Roser A, Schnepf N, Schumann D, Supersberger N, Zapp P (2008) Sozioökonomische Begleitforschung zur gesellschaftlichen Akzeptanz von Carbon Capture and Storage (CCS) auf nationaler und internationaler Ebene. Wuppertal et al

35. Luskin RC, Fishkin JS, Plane DL (1999) Deliberative Ppolling and Ppolicy Ooutcomes: Eelectric Uutility lissues in Texas. In: Paper presented at the annual meeting of the Midwest Political Science Association. Chicago, 4/ 1999 and at the annual meeting of the Association for Public Policy Analysis and Management, Washington DC, 11/1999. http://cdd.stanford.edu/ research/papers/2000/utility paper.pdf. Accessed 13 July 2012

36. De-Best Waldhober M, Daamen D, Faaij A (2009) Informed and uninformed public opinions on $\mathrm{CO}_{2}$ capture and storage technologies in the Netherlands. Int I Greenh Gas Con 3:322-332

37. Scheer D, Konrad W, Scheel O, Ulmer F, Hohlt A (2012) Fokusgruppen im Mixed-Method-Design: Kombination einer standardisierten und qualitativen Erhebung. In: Mack B, Renn O, Schulz M (ed) Fokusgruppen in der empirischen Sozialwissenschaft. Von der Konzeption bis zur Auswertung. Springer VS, Heidelberg, pp 148-168

38. Bloor M, Frankland J, Thomas M (2001) Focus groups in social research. Sage, London

39. Bürkli R (2000) Klimaänderung und Anpassungsprozesse im Wintertourismus. Publikation der Ostschweizerischen Geografischen Gesellschaft, Neue Folge, No. 6

40. Kitzinger J (1994) The methodology of focus groups: the importance of interaction between research participants. Sociol Health IIIn 16:103-121

41. Grudens-Schuck N, Allen BL, Larson K (2004) Focus group fundamentals. lowa State University Extension, Ames

42. Wuppertal Institut für Klima, Umwelt, Energie, Deutsches Zentrum für Luftund Raumfahrt, Zentrum für Sonnenenergie- und Wasserstoffforschung, Potsdam-Institut für Klimafolgenforschung (2007) RECCS: Strukturellökologisch-ökonomischer Vergleich Regenerativer Energien mit Carbon Capture and Storage, Wuppertal

43. BMU [Bundesministerium für Umwelt] (2008) BMU-Leitstudie: Weiterentwicklung der "Ausbaustrategie Erneuerbare Energien" vor dem Hintergrund der aktuellen Klimaschutzziele Deutschlands und Europas, Stuttgart.

44. Energiewirtschaftliches Institut der Universität Köln, Energy Environment Forecast Analysis (2008) Energiewirtschaftliches Gesamtkonzept 2030, Köln. http://www.ewi.uni-koeln.de/fileadmin/user_upload/Publikationen/Studien/ Politik_und_Gesellschaft/2008/EW_2008-03-31_Gesamtkonzept-2030.pdf. Accessed 13 July 2012

45. Europäische Kommission (2008) Einstellungen der europäischen Bürger zum Klimawandel. Spezial Eurobarometer 300, Brüssel. http://ec.europa.eu/ public_opinion/archives/ebs/ebs_300_full_de.pdf. Accessed 13 July 2012

46. Küchler M (1979) Multivariate Analyseverfahren. Teubner, Stuttgart

47. Bots PWG, van Daalen CE (2008) Participatory model construction and model use in natural resource management: a framework for reflection. Syst Pract Act Res 21:389-407

48. Dreyer M, Renn O (2011) Participatory approaches to modelling for improved learning and decision-making in natural resource governance: an editorial. Environ Policy Gov 21:379-385

doi:10.1186/2192-0567-3-8

Cite this article as: Scheer et al:: Public evaluation of electricity technologies and future low-carbon portfolios in Germany and the USA. Energy, Sustainability and Society 2013 3:8.

\section{Submit your manuscript to a SpringerOpen ${ }^{\circ}$ journal and benefit from:}

- Convenient online submission

- Rigorous peer review

- Immediate publication on acceptance

- Open access: articles freely available online

- High visibility within the field

- Retaining the copyright to your article

Submit your next manuscript at $>$ springeropen.com 